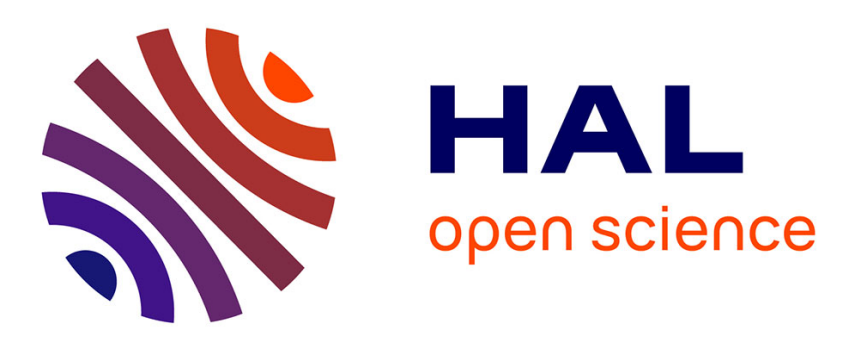

\title{
A climatological database of the Linke turbidity factor
}

Joel Angles, Lionel Ménard, Olivier Bauer, Christelle Rigollier, Lucien Wald

\section{To cite this version:}

Joel Angles, Lionel Ménard, Olivier Bauer, Christelle Rigollier, Lucien Wald. A climatological database of the Linke turbidity factor. ISES Solar World Congress 1999, Jul 1999, Jerusalem, Israel. pp.432-434. hal-00465886

\section{HAL Id: hal-00465886 \\ https://hal-mines-paristech.archives-ouvertes.fr/hal-00465886}

Submitted on 22 Mar 2010

HAL is a multi-disciplinary open access archive for the deposit and dissemination of scientific research documents, whether they are published or not. The documents may come from teaching and research institutions in France or abroad, or from public or private research centers.
L'archive ouverte pluridisciplinaire HAL, est destinée au dépôt et à la diffusion de documents scientifiques de niveau recherche, publiés ou non, émanant des établissements d'enseignement et de recherche français ou étrangers, des laboratoires publics ou privés. 
Angles J., Menard L., Bauer O., Rigollier C., Wald L., 1999. A climatological database of the Linke turbidity factor. In Proceedings of the ISES Solar World Congress 1999, Jerusalem, Israel, July 4-9, 1999, volume I, pp 432-434.

\title{
A CLIMATOLOGICAL DATABASE OF THE LINKE TURBIDITY FACTOR
}

\author{
Joel Angles, Lionel Ménard, Olivier Bauer, Christelle Rigollier and Lucien Wald \\ Groupe T\&M, Centre d'Energétique, Ecole des Mines de Paris, BP 207, 06904 Sophia Antipolis cedex, France, \\ Phone: +33 4939574 49, Fax: +33 4939575 35, lucien.wald@ cenerg.cma.fr
}

\begin{abstract}
The Linke turbidity factor is an important parameter in solar radiation studies. Long-term monthly average values, $\mathrm{TL}_{\mathrm{m}}$, are sufficient for most applications. Estimates of $\mathrm{TL}_{\mathrm{m}}$ may be obtained by way of a linear regression established for several European sites between the sum of the Angström regression coefficients on a monthly basis $\left(a_{m}+\right.$ $b_{m}$ ) and the measured $\mathrm{TL}_{\mathrm{m}}$. During the European Solar Radiation Atlas (ESRA) project, values of $\mathrm{a}_{\mathrm{m}}$ and $\mathrm{b}_{\mathrm{m}}$ have been obtained for 710 sites in Europe and countries surrounding the Mediterranean sea, from the analysis of measurements made during the period 1981-1990. Using the above-mentioned formula, these values are turned into climatological values of TL for each month of the year. This data set of TL is unique in the world and attention has been paid to the means of disseminating the resulting information. A World Wide Web site "Helioserve" has been established, which offers an access to the database through a standard HTML interface. The customers of the Helioserve site are professionals, in research or industry. The database outputs are used as inputs into their own models for atmospheric optics. The site Helioserve comprises also a numerical simulation aspect, which provides to the customer, estimates of the clear sky radiation by running the clear-sky model of the ESRA. The TL values requested by the model can be supplied by either the database using an internal query, or the customer himself, or can be set to default values.
\end{abstract}

\section{INTRODUCTION}

The Linke turbidity factor (TL, for an air mass equal to 2 ) is a very convenient approximation to model the atmospheric absorption and scattering of the solar radiation under clear skies. It describes the optical thickness of the atmosphere due to both the absorption by the water vapour and the absorption and scattering by the aerosol particles relative to a dry and clean atmosphere. It summarises the turbidity of the atmosphere, and hence the attenuation of the direct beam solar radiation (WMO, 1981; Kasten, 1996). The larger TL, the larger the attenuation of the radiation by the clear sky atmosphere.

The Linke turbidity factor is an important parameter in solar radiation studies. It can be obtained directly from observations performed during very clear sky periods, but this kind of experimental data is rarely available, thus TL is generally an estimated parameter. Also, time series of radiation data are generally too short to allow estimation on a daily basis. Fortunately, long-term monthly average values, $\mathrm{TL}_{\mathrm{m}}$, are sufficient for most applications. Several methods for estimating $\mathrm{TL}_{\mathrm{m}}$ values can be found in the literature: for example from time series of daily global horizontal irradiation (Aguiar, in ESRA 1999); from monthly Angström sum (Page, 1986); from subjective assessments of the type of atmospheric conditions prevailing in the region of interest (linear regression with latitude and with the Atmospheric Turbidity Index, Dogniaux and Lemoine, 1983).

\section{A CLIMATOGICAL DATABASE OF TL}

In our case, estimates of $\mathrm{TL}_{\mathrm{m}}$ are obtained by way of a linear regression established for several European sites by Page (European Solar Radiation Atlas ESRA, 1999) between the sum of the Angström regression coefficients on a monthly basis $\left(\mathrm{a}_{\mathrm{m}}\right.$ $+b_{m}$ ) and the measured $T_{m}$.

The equation used to obtain the $\mathrm{TL}_{\mathrm{m}}$ values from the Angström sums (in month $m$ ) is:

$\mathrm{TL}_{\mathrm{m}}=\mathrm{f}_{\mathrm{m}}\left[1-\left(\mathrm{a}_{\mathrm{m}}+\mathrm{b}_{\mathrm{m}}\right)\right]$

The factor $f_{m}$ is chosen from the Table 1 , and is a function of the month.

\begin{tabular}{|c|c|c|c|c|c|c|}
\hline & Jan & Feb & Mar & Apr & May & Jun \\
\hline $\mathrm{f}_{\mathrm{m}}$ & 10.7 & 13.2 & 15.4 & 17.1 & 18.6 & 16.9 \\
\hline \multicolumn{7}{|c|}{} \\
\cline { 2 - 7 } & Jul & Aug & Sep & Oct & Nov & Dec \\
\hline $\mathrm{f}_{\mathrm{m}}$ & 18.2 & 17.0 & 14.9 & 12.9 & 11.3 & 9.5 \\
\hline
\end{tabular}

Table 1. Recommended values of factor $\mathrm{f}_{\mathrm{m}}$ for monthly mean radiation computations.

Strictly speaking, this Equation provides a mean value (or climatological value) of the monthly air mass 2 Linke turbidity factor, $\mathbf{T L}_{\mathbf{m}}$, estimated from the mean value of the monthly Angström sum.

In the framework of the ESRA project, values of $a_{m}$ and $b_{m}$, have been obtained for 710 sites in Europe and Mediterranean countries, either by directly using observed daily global radiation and daily sunshine data for the site month by month, or interpolated using values from nearby sites (ESRA, 1999). Sums of $a_{m}$ and $b_{m}$ can thus be derived over the period 19811990 to compute $\mathrm{TL}_{\mathrm{m}}$ values at the same sites, using the abovementioned formula. Actually, we consider that what we have computed are climatological values of TL for each month of the year, for the period 1981-1990. 
The Linke turbidity factor experiences large variations in time. These climatological values do not offer an accurate account of these variations; care should be taken on their use. It has been decided to give the values with only one decimal (e.g., 3.6), but this does not mean that the accuracy on these climatological values is of order of 0.05 . Indeed the accuracy is unknown since there is no information available in ESRA about the accuracy of the relationship between the sum of the Angström coefficients and the Linke turbidity factor or about the accuracy of the assessment of the sum of the Angström coefficients. This is presently the most worrying aspect of the database.

\section{DESIGN OF THE DATABASE}

The database is constituted by a list of geographical sites with assessment of the Linke turbidity factor. These stations are spread throughout Europe. For each station, monthly values of the Linke turbidity factor are available, that is twelve values per station. The database comprises two files:

- a file taking stock characteristics about the site, containing the WMO number of the station, its name and its geographical co-ordinates and elevation, plus additional parameters for a better management,

- and a file, which contains the WMO number of the station and the twelve, associated TL values.

As a database manager, mini SQL (mSQL) (http://www.Hugues.com.au) was selected. This relational database package is free for educational bodies, such as Ecole des Mines de Paris. The mSQL database only allows a subset of ANSII SQL (Standard Query Language) query language but we did not yet face any limitation for our project. As mentioned by their authors the philosophy of mSQL has been to provide a database management system capable of rapidly handling simple task. mSQL also includes various tools like a C API allowing any $\mathrm{C}$ program to communicate with the database, a www interface, called W3-mSQL, and a scripting language called "Lite".

\section{DISSEMINATION OF THE INFORMATION}

This data set of TL is unique in the world. Because of the large efforts devoted to such a collection, attention has been paid to the means of disseminating the resulting information. The World Wide Web is such a dissemination tool. A web site: the Helioserve server (www-helioserve.cma.fr) has been designed, which aims at providing the known values of $\mathrm{TL}$ (Angles et al. 1998).

The Helioserve server was built up by taking into account two aspects:

1. A database query aspect. It is the ability of the server to supply the customer with the TL values, which are extracted from the database.

2. A numerical simulation aspect. It offers an access to other resources, such as models, using parameters supplied by the database or by the customer himself, or set to default values.
The Figures 1 and 2 present two HTML pages for requesting values of TL: the query page and the resulting page.

The Helioserve server relies on a set of software that is called by an http server in response to user requests. The $T_{L}$ values are stored into a relational database. The system interface allows a user to send a query to the web server through HTML (HyperText Mark-up Language, http://www.w3.org/MarkUp) documents based on a form (http://www.ncsa.uiuc.edu/ SDG/Software/Mosaic/Docs/fill-out-forms/overview.html).
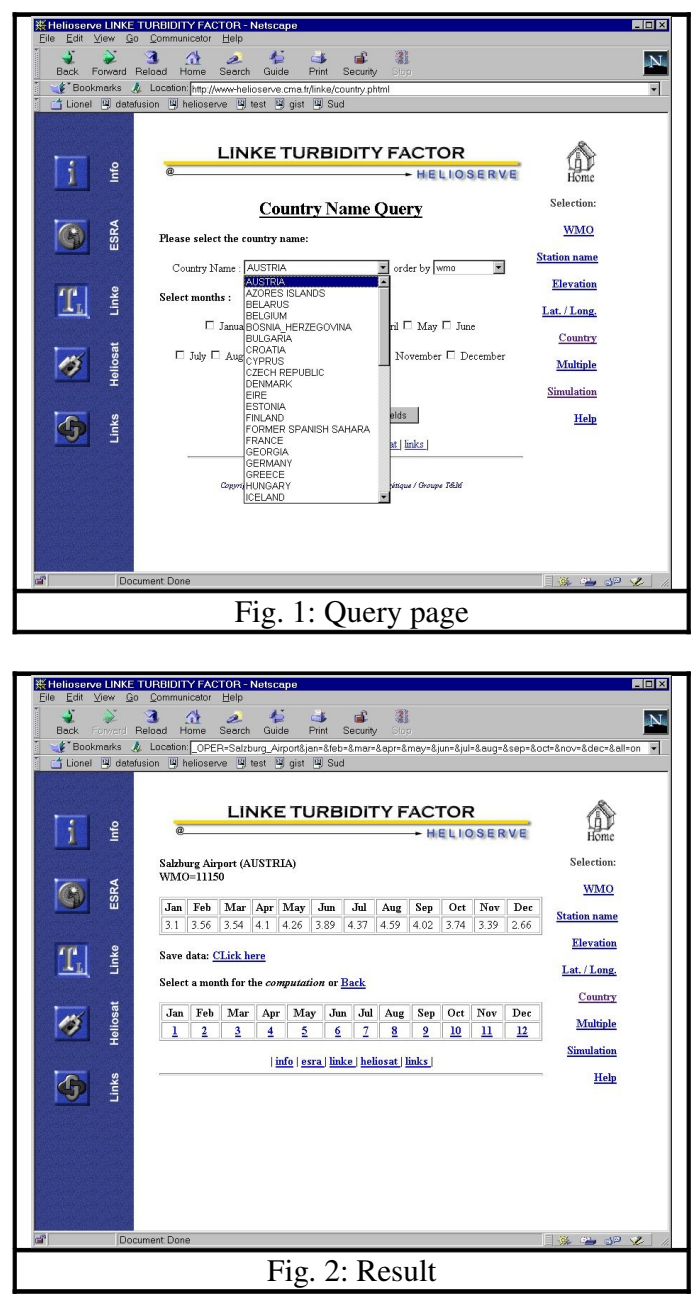

This HTLM page calls a template that includes SQL statements as well as conditional instruction and HTML tag for the output. The Helioserve server uses an Apache (http://www.apache.org) web server. The Apache server is powerful and flexible. It is highly configurable and allows extension to third party modules. It is the most used server with more than $45 \%$ of the overall web server on Internet. It is part of a huge consortium deeply committed into its development and maintenance. Moreover it is free.

The missing link of the system is the scripting language that will handle the HTML-based form query of the user and transfer it to the mSQL database. Despite the above-mentioned "Lite" scripting language included with mSQL, we have preferred another tool for our script development. 
Angles et al. (1998) discussed several options for this scripting language. Despite the availability of the scripting language Lite included with $\mathrm{mSQL}$, the PHP/FI tool (http://php.iquest.net) was preferred. PPH/FI is a server-side html-embedded scripting language. That means that a simple script can be written directly into html files; it offers a fast and powerful alternative to CGI programming. There is no static HTML pages stored into the web server. All the pages are dynamically built upon user request. An extensive description of the server with examples (HTML-publication) is given in Angles et al. (1998).

The customers of the Helioserve site are presently researchers involved in studies of solar radiation parameters. They precisely know what is TL, and the database outputs act as inputs into their own models for atmospheric optics. The database query aspect of the Helioserve site perfectly fits their needs by supplying them with the TL values extracted from the database for the requested site.

\section{VALUE-ADDED INFORMATION}

A larger class of customers has been targeted. It is made up of professionals, in research or industry, who request an assessment of some quantities related to the solar radiation, which may not be measurements. For example, the maxima of the solar radiation available at ground level may be requested for e.g., the sizing of a solar system for domestic water heating. The Helioserve server comprises a numerical simulation aspect. It offers an access to other resources, such as models, and provides value-added information.

For example, not all customers care about values of TL, though it is an important parameter for the assessment of the solar radiation for clear skies. They should be supplied with the relevant parameters, which are to be computed from the present database. The numerical simulation aspect of the Helioserve site serves this purpose. Presently it is able to provide to the customer, estimates of the clear sky radiation by running the clear-sky model of ESRA (1999). The TL values requested by the model can be supplied by either the database using an internal query, or the customer himself, or set to default values.

The clear-sky model software was written in C language and has been tailored to suit the web application. Modifications have only been made on the output section of the source program. The simulation can be executed at different places into the Helioserve server and different schemes are possible:

1. It fetches some parameters from the result of a query made by the user, and asks for two more parameters (the day and the year) for computation

2. Or the user can manually feed the empty fields with his own parameters. In particular, this allows assessing the sensitivity of the results to the input parameters. Among others, Rigollier et al. (1999) made an extensive use of this aspect of the Helioserve server to assess the potentials of this ESRA model with respect to the Heliosat method for the computation of the global radiation from satellite images.

\section{CONCLUSION}

The realisation of the new European Solar Radiation Atlas (ESRA) has provided an opportunity to create a database of the Linke turbidity factor, which is unique in the world. Special attention has been brought to the dissemination of this information, which is not included in the ESRA package.

The availability of free software has enabled the authors to build up a web server giving access to this database. The database is very simple and most of the efforts have been put on the management of the queries through the web as well as on the user interface. Though our team may be considered as trained in all the aspects related to the Helioserve server, the amount of efforts was more important than expected.

Collection of data is already known as being a large burden, dissemination is another one. However it is rewarding because many users have already praised its existence; it is currently the easiest and cheapest way to obtain the Linke turbidity factor as well as simulations of the available solar energy under clear sky. The database has also been used to establish the server Satel-Light (http://satel-light.entpe.fr) which delivers values of global radiation and daylighting information for Europe. The Helioserve server is operating for 1.5 year now. Statistics of exploitation shows that there are 30 hits per day as anerage. The average amount of information transferred per day is 330 Kbytes. This proves its usefulness.

The whole system has also proved its reliability. It is simple to administrate and new features can be added like new templates without any repercussion on the overall system. The Helioserve server is evolving and will offer more information on solar radiation and also related software. In particular, more sites should be added with TL values. Such values are difficult to obtain in the literature, but an effort is on going to collect them. The database has presently a unique source of information: the European Solar Radiation Atlas. Since other sources are presently taken into account, the database will be slightly re-designed to integrate more parameters describing the content of the database and the sources of information (e.g., provider, period, etc.).

\section{REFERENCES}

Angles J., Menard L., Bauer O. and Wald L. (1998). In Proceedings of the Earth Observation \& Geo-Spatial Web and Internet Workshop '98, Josef Strobl \& Clive Best Eds, Salzburger Geographischen Materialen, Universitat Salzburg, Salzburg, Austria, Heft 27, pp. 33-34.

Dogniaux R. and Lemoine M. (1983). In: W. Palz (Ed.), Solar Energy R\&D in the European Community, Series F, Vol. 2, Solar Radiation Data. D. Reidel Publ., Dordrecht, pp. 94-107. ESRA: European solar radiation atlas (1999), includ. CDROM. Published for the Commission of the European Communities by Presses de l'Ecole, Ecole des Mines de Paris, Paris, France.

Kasten F. (1996). The Linke turbidity factor based on improved values of the integral Rayleigh optical thickness. Solar Energy, 56 (3), 239-244.

Page, J.K., Ed., (1986). Prediction of solar radiation on inclined surfaces. Solar Energy R\&D in the European Community, 
Series F, Vol. 3, Solar Radiation Data, D. Reidel Publishing Compagny, Dordrecht, Holland.

Rigollier C., Bauer O. and Wald L. (1999). On the clear sky model of the $4^{\text {th }}$ European Solar Radiation Atlas with respect to the Heliosat method. Solar Energy, in press.

World Meteorological Organization (WMO) (1981). Technical Note No. 172, WMO-No. 557, Geneva, Switzerland, pp. 121123. 